\title{
Changes in abscisic acid during leaf yellowing of cut stock flowers
}

\author{
A. Ferrante ${ }^{1, *}$, P. Vernieri ${ }^{2}$, G. Serra ${ }^{3}$ and F. Tognoni ${ }^{2}$ \\ ${ }^{1}$ Department of Crop Science, University of Milan, Italy; ${ }^{2}$ Dip. Biologia Piante Agrarie, Viale delle Piagge, \\ 23, University of Pisa, Italy; ${ }^{3}$ Scuola Superiore S. Anna, Pisa, Italy; *Author for correspondence: Diparti- \\ mento di Produzione Vegetale,Via Celoria, 2 CAP 20133 (e-mail: antonio.ferrante@unimi.it; phone: + 39- \\ 050-945500; fax: + 39-02-50316575)
}

Received 18 June 2003; accepted in revised form 4 June 2004

Key words: ABA, Carotenoids, Leaf yellowing, Matthiola incana, Post-harvest

\begin{abstract}
Leaf pigments, such as chlorophyll and carotenoids, are essential plant molecules. They provide carbohydrates and energy during all plant life. Leaf pigments are also important parameters of decorative plants, such as floriculture items, cut foliage and flowers. Leaf yellowing is a form of senescence caused by an internal hormone imbalance, such as a lack of cytokinins. The aim of this study was to investigate the changes in total carotenoids and endogenous ABA in cut flower stock leaves during post-harvest life. The effect of pulse treatment with 5 or $10 \mu \mathrm{M}$ thidiazuron (TDZ), $150 \mathrm{mg}^{-1}$ 8-hydroxyquinoline sulphate (8-HQS) and combinations of TDZ with 8-HQS on total carotenoids and ABA concentration was also investigated. Results showed that total carotenoids drastically decreased from $1548 \mu \mathrm{g} \mathrm{cm}^{-2}$, until reaching $565 \mu \mathrm{g} \mathrm{cm}^{-2}$ at the end of vase life. Endogenous ABA strongly increased at the same time, going from $167 \mathrm{ng} \mathrm{g}^{-1} \mathrm{DW}$ at the beginning of the experiment to $1322 \mathrm{ng} \mathrm{g}^{-1} \mathrm{DW}$ at the end of vase life. The TDZ inhibited carotenoid degradation, but did not affect the ABA concentration, while the 8-HQS did not prevent carotenoid degradation and the ABA concentration was only slightly affected. ABA seems to be a secondary senescence bio-product that may have a synergic effect with other senescence inducers dramatically accelerating leaf senescence.
\end{abstract}

Abbreviations: 8-HQS - 8-hydroxyquinoline sulphate; ABA - abscisic acid; TDZ - thidiazuron ( $N$-phenyl$N^{\prime}$-1,2,3-thiadiazol-5-yl urea)

\section{Introduction}

Leaf yellowing is a visible marker of senescence as leaves lose their chlorophyll content. The loss of chlorophyll causes a shift in colour from green to a wide variety of yellow, red, brown and orange (Matile 2000). The economic value of many ornamental plants is directly correlated to their leaf colour, and cut flowers with yellow leaves cannot be marketed. Chlorophyll loss is accompanied by the degradation of other leaf pigments, such as carotenoids. Carotenoids are also a precursor for $\mathrm{ABA}$ biosynthesis and their degradation may be involved in leaf yellowing. The production of ABA by carotenoids is known as indirect $\mathrm{C}_{40} \mathrm{ABA}$ biosynthesis and has been studied in cell-free systems using labeled carotenoids (Cowan and Richardson 1993; Lee and Milborrow 1997a). The initial step is the reaction of isopentenyl diphosphate with dimethylallyl diphosphate, to yield geranylgeranyl diphosphate (Milborrow 2001). This initial step leads not only to carotenoids, but 
also to other numerous isoprenoids, such as chlorophylls, tocopherols (mainly photosynthetic pigments), hormones (ABA, gibberellins and cytokinins) and anti-pathogens (phytoalexins).

The role of endogenous ABA during leaf senescence is still under investigation. It has been demonstrated that exogenous applications of $100 \mu \mathrm{M}$ ABA to wild type Arabidopsis and an ethylene-resistant mutant induced leaf yellowing (Zacarias and Reid 1990). Molecular analysis has shown that the application of ABA to Arabidopsis increased the expression of almost $50 \%$ of the senescence associated genes (SAGs 12, 13, 17, ERD1 and RD21) and the response to ABA increases with leaf age (Weaver et al. 1998).

The relationship between ABA and leaf yellowing has not been studied with references to the involvement of carotenoids.

It is well known that leaf yellowing can be inhibited using some plant growth regulators or substances with hormone-like activity. Inhibitors of chlorophyll degradation, such as cytokinins and gibberellic acid, are able to delay leaf yellowing in some sensitive cut flowers like Alstroemeria, Lilium and other potted plants (Hicklenton 1991; BenJacoov et al. 1985). Among the inhibitors of leaf yellowing, thidiazuron (TDZ) has been found to be effective in cut Alstroemeria flowers (Ferrante et al. 2002a, b). Alstroemeria leaves treated with TDZ do not show any symptom of senescence for over 4 months (Ferrante et al. 2002a).

In this study, we investigated the variation of endogenous ABA during post-harvest induced senescence in cut stock flowers treated with thidiazuron, with or without a biocide that prevents bacteria occlusion. Bacteria in the vase water induce water stress and may promote ABA biosynthesis. 8-Hydroxyquinoline sulphate (8-HQS), which is commonly marketed for preserving cut flowers, was used as a biocide (see review, van Doorn 1997). The aim of this work was to identify a possible correlation between carotenoids and ABA concentration.

\section{Materials and methods}

\section{Plant material}

Stock (Matthiola incana L.) flowers were bought directly from a cooperative of flower growers (Florexport, Viareggio Italy). Cut flowers were selected to avoid malformations or damage related to harvesting and transport handling. Flower stems were cut to $60 \mathrm{~cm}$ and placed in distilled water. All experiments were performed in a postharvest room equipped with a controlled environment maintained at $20{ }^{\circ} \mathrm{C}, 60 \%$ relative humidity and $15 \mu \mathrm{mol} \mathrm{m} \mathrm{m}^{-2} \mathrm{~s}^{-1}$ light intensity for $12 \mathrm{~h} \mathrm{day}^{-1}$ by cool-white fluorescent lamps.

\section{Treatments}

Flowers were placed in distilled water (control) or in a vase solution containing 5 , or $10 \mu \mathrm{M}$ thidiazuron (TDZ, Duchefa), $150 \mathrm{mg}^{-1} 8$-HQS or the combination $150 \mathrm{mg}^{-1} 8$-HQS with 5 or $10 \mu \mathrm{M}$ TDZ and $100 \mu \mathrm{M}$ ABA (Sigma, Italy). Flowers were pulse treated for $24 \mathrm{~h}$ in the post-harvest laboratory under the conditions described above. After the pulse treatment, all the flowers were placed in distilled water. The entire experiment was repeated twice. The experiment was considered over after 14 days, when control flowers were dead.

Leaf senescence, leaf relative water content, total chlorophyll and carotenoids

Leaf senescence was determined by daily observation of cut flower leaves. Leaf water status was expressed as relative water content (RWC) calculated according to Pardossi et al. (1991). Total chlorophylls and carotenoids were determined from $10 \mathrm{~mm}$ diameter discs (three discs for each sample). Leaf pigments were extracted using $99 \%$ methanol and samples were kept in darkness at $4{ }^{\circ} \mathrm{C}$ for $24 \mathrm{~h}$. The absorbance readings were taken at 665.2, 652.4 and $470 \mathrm{~nm}$. Total chlorophyll and carotenoid contents were calculated as described by Lichtenthaler (1987).

\section{Endogenous $A B A$ analysis and validation of $R I A$ results}

Leaf samples (80-100 mg FW) were collected, weighed, immediately frozen in liquid nitrogen and stored at $-20^{\circ} \mathrm{C}$ until needed. Samples were extracted with distilled water (water:tissue ratio 10:1 v/w) for $16 \mathrm{~h}$ at $4{ }^{\circ} \mathrm{C}$ in the dark. Quantitative analysis was performed on crude aqueous extracts 
using a solid-phase radioimmunoassay based on a monoclonal antibody (DBPA1) raised against free (S)-ABA, as described previously (Vernieri et al. 1991).

We investigated the presence of competitive interferences in crude aqueous extracts by HPLC fractionation using an LDC instrument equipped with a UV absorbance detector operating at $254 \mathrm{~nm}$. A column $(15 \mathrm{~cm} \times 1 / 4$ in. OD $)$ packed with LiChrosorb RP 18, $10 \mu \mathrm{m}$ was used. The

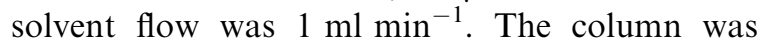
eluted as follows: $30 \%$ methanol in water $(0.05 \mathrm{M}$ acetic acid) for $6 \mathrm{~min}$; a linear gradient $30-50 \%$ methanol for $20 \mathrm{~min}$; $50 \%$ methanol for $6 \mathrm{~min}$; a linear gradient $50-100 \%$ methanol for $15 \mathrm{~min}$. Fractions of $2 \mathrm{ml}$ were collected, evaporated under vacuum, and the residue resuspended in PBS buffer ( $\mathrm{pH} 7)$. Each fraction was assayed in triplicate by RIA. The results showed the absence of significant competitive interferences, most of the immunoreactivity being located in the ABA fraction (data not shown).

Noncompetitive interferences were evaluated by internal standardization experiments. Aliquots of crude aqueous extract were added to standards, and the ABA quantities recovered were plotted against the amount of ABA added, in order to check the parallelism of the lines obtained. Results indicate the absence of noncompetitive interferences (data not shown).

\section{Statistical analysis}

The data are reported in figures and tables as means with standard deviation (SED). The data were subjected to two-way analysis of variance and the differences among treatments were analyzed by Bonferroni post-test $(p<0.05)$. Each treatment was composed of six replicate stems. Correlation analysis was performed using Excel statistical tools (Microsoft software).

\section{Results}

Leaf senescence and leaf relative water content

Cut stock flowers placed in distilled water showed leaf yellowing after 5-6 days after harvest, while

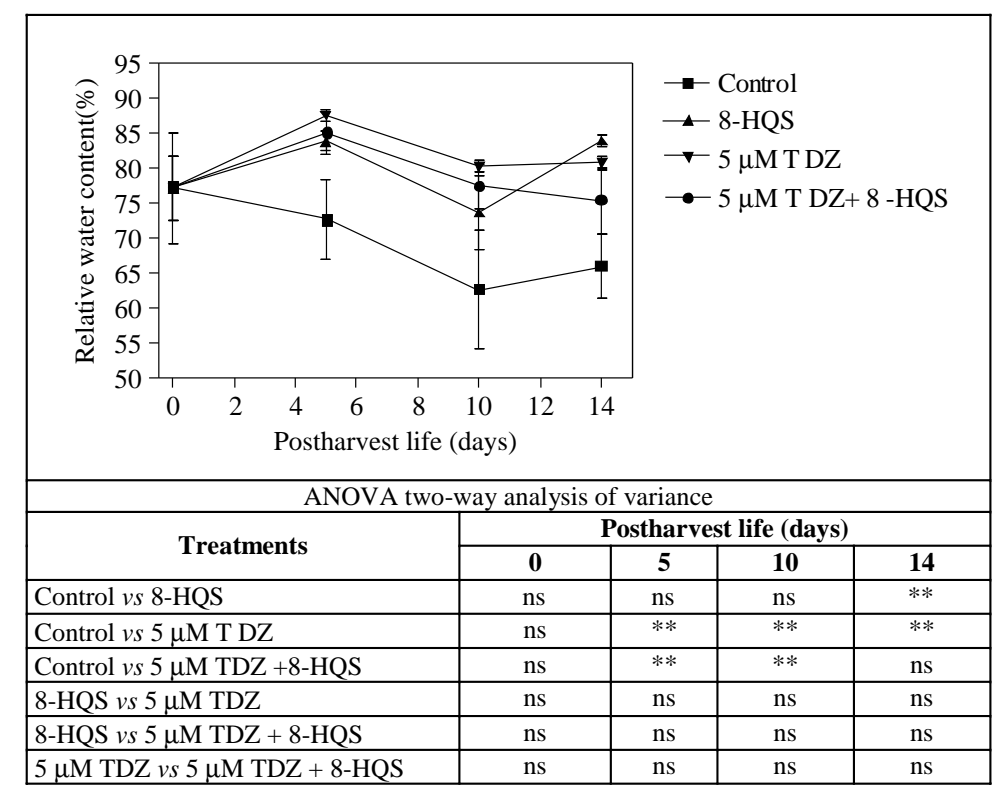

Figure 1. Relative water content (RWC) of cut stock leaves (Matthiola incana) harvested from cut flowers pulse treated for $24 \mathrm{~h}$ with distilled water (control), $150 \mathrm{mg} \mathrm{l}^{-1} 8$-HQS, $5 \mu \mathrm{M}$ TDZ or $5 \mu \mathrm{M} \mathrm{TDZ}+150 \mathrm{mg} \mathrm{l}^{-1} 8$-HQS. After the pulse treatment the vase solutions were replaced with distilled water. Values are the means $\pm \mathrm{SD}$ of six leaves randomly harvested at $0,3,5,10$ and 14 days since when cut flowers where placed in vase. Data were subjected to two-way analysis of variance and differences among treatments were analyzed by Bonferroni post-test. Each treatment was compared to all the other treatments. The asterisks denote significant differences at $* p<0.05, * * p<0.01$ and ${ }^{* * *} p<0.001$. 
cut stems treated with ABA showed leaf yellowing as early as 2 days after treatment. Other treatments delayed leaf senescence, especially TDZ. Both TDZ concentrations tested (5 and $10 \mu \mathrm{M}$ ) inhibited leaf yellowing over the entire 14 days of experimentation (cut flowers treated with TDZ left in the post-harvest room did not show any leaf yellowing for over 2 months, data not shown), while 8-HQS and the combinations (TDZ + 8-HQS) only delayed senescence for a few days. The leaf relative water content decreased with the progressive senescence of control flowers, while it did not statistically change among the treatments (Figure 1).

\section{Total chlorophyll content}

Chlorophyll content was measured to give a quantifiable parameter of the progressive leaf yellowing. Exogenous applications of ABA induced a dramatic decline in chlorophyll concentration immediately after a $24 \mathrm{~h}$ treatment, reaching $3.7 \mu \mathrm{g} \mathrm{cm}^{-2}$. An analogous amount of chlorophyll was found in leaves of control flowers at 14 days (Figure 2). The decline in chlorophyll in control flower leaves was visible after 5 days of vase life compared to other treatments. It was estimated that leaf yellowing was visible when the leaf chlorophyll content decreased to $20 \mu \mathrm{g} \mathrm{cm}^{-2}$. Treatment with 8-HQS did not preserve the chlorophyll content, even if the degradation rate was lower than in the control and the chlorophyll concentration were constantly higher than in control cut flowers. The combination of $8-\mathrm{HQS}$ and TDZ delayed the chlorophyll loss by 10 days, after which started to decline (Figure 2). The treatments with TDZ alone maintained chlorophyll concentration.

\section{$A B A$ and total carotenoids}

Leaf $\mathrm{ABA}$ and total carotenoid concentration in untreated cut flowers after 14 days, were shown to change in different directions; ABA increased while carotenoids decreased (Figure 3). Total carotenoids in cut stock leaves at the beginning of the experiment were $1548 \mu \mathrm{g} \mathrm{cm}^{-2}$ and decreased reaching $565 \mu \mathrm{g} \mathrm{cm}^{-2}$ at the end of vase life. On the contrary, the initial ABA concentration was
$167 \mathrm{ng} \mathrm{g}^{-1}$ DW and rapidly increased, during the experiment, until reaching $1322 \mathrm{ng} \mathrm{\textrm {g } ^ { - 1 }} \mathrm{DW}$ in senescing control leaves at the end of the experiment. During the first 5 days, the ABA increased by $37 \%$ and the carotenoids decreased by $38 \%$. By day 10 of vase life, the ABA concentration had sharply increased, reaching $1250 \mathrm{ng} \mathrm{g}^{-1}$ of DW, then remaining constant after 14 days (Figure 3). Correlation analysis between total carotenoids and ABA showed that they were negatively correlated with $r$ value of -0.82 and $R^{2}=0.68$ (Figure 4). The correlation was statistically significant at $p \leq 5 \%$.

The endogenous $\mathrm{ABA}$ in leaves of cut flowers treated with 8-HQS was higher than in other treatments and statistically different $(p<0.05)$ at 10 days compared to 5 and $10 \mu \mathrm{M}$ TDZ (Table 1).

Total carotenoid changes were similar to total chlorophyll variations during post-harvest life. ABA treated flowers lost $70 \%$ of their total carotenoids after 3 days compared to the initial value at harvest time (Figure 5). The carotenoid degradation rate of leaves sampled from 8-HQS treated flowers was not different from that found in control leaves, except at 14 days, when the amount of carotenoids was statistically lower (Figure 5). On the contrary, leaves sampled from cut flowers treated with $5 \mu \mathrm{M}$ TDZ alone or combined with 8HQS did not show any significant variation in total carotenoids. Treatments performed using $10 \mu \mathrm{M}$ TDZ did not show any additional benefit compared to treatments using $5 \mu \mathrm{M} \mathrm{TDZ}$, and data recorded from the higher TDZ concentration showed the same trend as that obtained from $5 \mu \mathrm{M}$ TDZ (data not shown).

\section{Discussion}

Cut stock flowers were used as a model system for leaf yellowing studies. Leaves become yellow within 7 days after harvest. It is believed that detached flowers do not receive cytokinins, because the major biosynthesis site is located in roots (van Staden et al. 1988; Crozier et al. 2000). Therefore, a hormone imbalance occurs and the first visible physiological expression of this disorder is chlorophyll degradation. However, chlorophyll catabolism is tightly associated with leaf carotenoid concentration. Chlorophylls are naturally sensitive to visible radiation and, if they are not protected, 


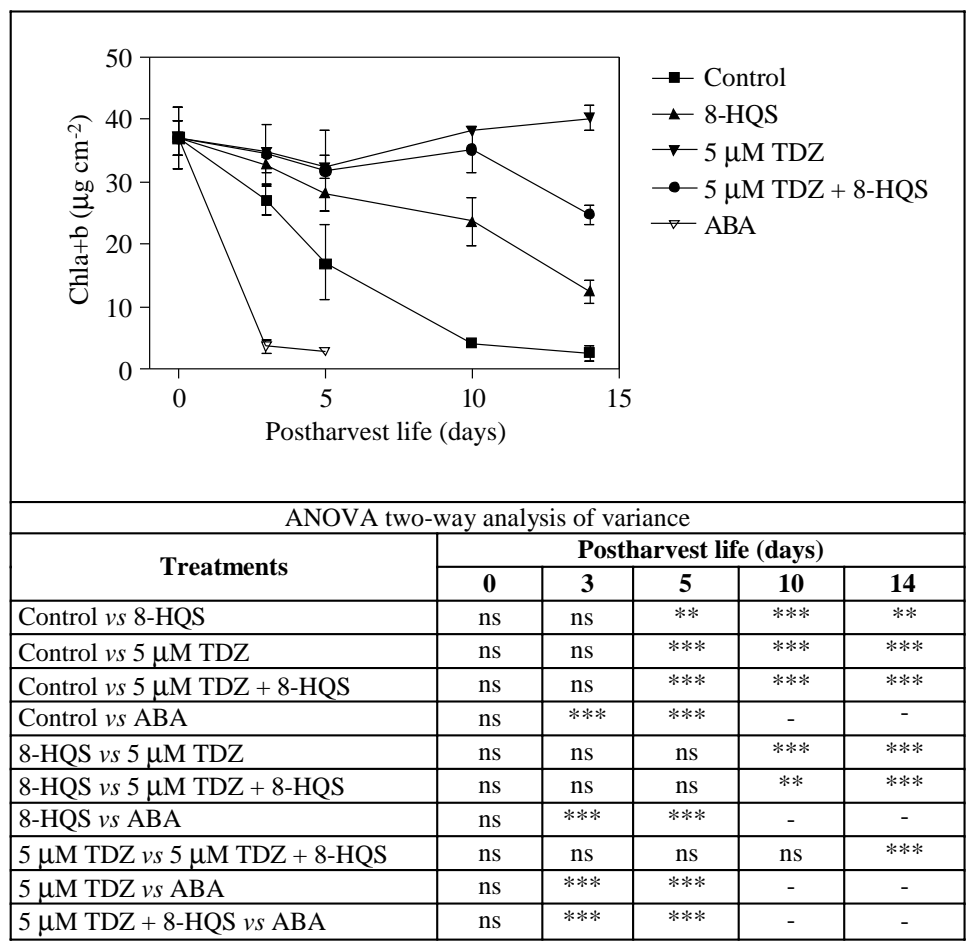

Figure 2. Total chlorophyll concentration $\left(\mu \mathrm{g} \mathrm{cm}^{-2}\right)$ of cut stock leaves harvested from cut flowers pulse treated for $24 \mathrm{~h}$ with distilled water (control), $150 \mathrm{mg}^{-1} 8$-HQS, $5 \mu \mathrm{M}$ TDZ or $5 \mu \mathrm{M} \mathrm{TDZ}+150 \mathrm{mg} \mathrm{l}^{-1} 8$-HQS and $100 \mu \mathrm{M}$ ABA. After the pulse treatment the vase solutions were replaced with distilled water. Values are the means $\pm \mathrm{SD}$ of six leaves randomly harvested at $0,3,5,10$ and 14 days since when cut flowers where placed in vase. Data were subjected to two-way analysis of variance and differences among treatments were analyzed by Bonferroni post-test. Each treatment was compared to all the other treatments. The asterisks denote significant differences at $* p<0.05,{ }^{* *} p<0.01$ and ${ }^{* * *} p<0.001$.

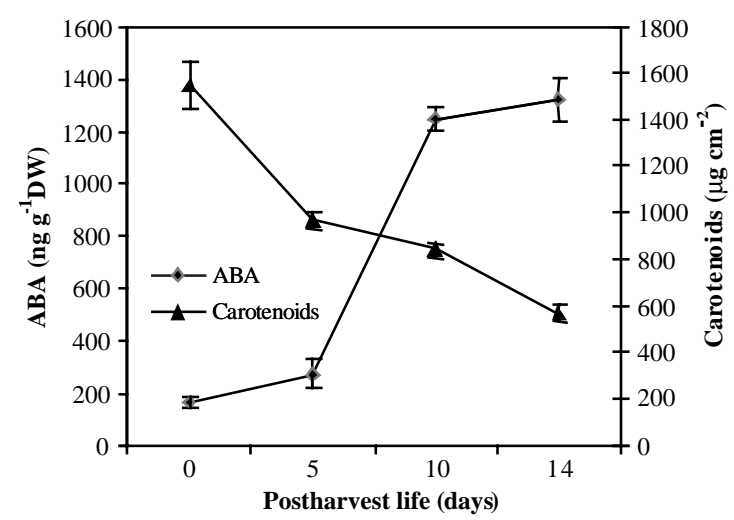

Figure 3. Total carotenoids $\left(\mu \mathrm{g} \mathrm{cm}^{-2}\right)$ and endogenous ABA (ng $\mathrm{g}^{-1}$ ) concentration changes in cut stock leaves (Matthiola incana) harvested from cut flowers during post-harvest life. Values are the means \pm SD of 6 leaves randomly harvested at $0,5,10$ and 14 days since when cut flowers where placed in vase (post-harvest life).

start to degenerate within a very short period of time, (Biswall 1995; Niyogi et al. 1998). Carotenoids are indispensable in protecting the

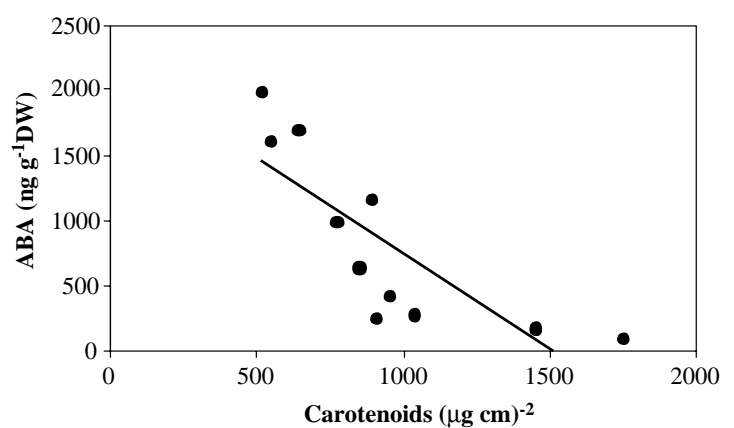

Figure 4. Correlation analysis between total carotenoids $\left(\mu \mathrm{g} \mathrm{cm}^{-2}\right)$ and endogenous ABA ( $\left.\mathrm{ng} \mathrm{g}^{-1}\right)$ concentration in cut stock leaves (Matthiola incana) harvested from cut flowers during post-harvest life. The correlation was significant at $5 \%$.

photosynthetic machinery from photooxidative damage (Demmig-Adams et al. 1996). Leaves of cut stock control flowers showed that ABA dramatically increases during leaf yellowing and total carotenoids decrease at the same time. This result suggests that during leaf yellowing, carotenoids 
Table 1. Endogenous ABA concentration ( $\mathrm{ng} \mathrm{g}^{-1} \mathrm{DW}$ ) in leaves of cut stock (Matthiola incana) pulse treated for $24 \mathrm{~h}$ with distilled water (control), $150 \mathrm{mg}^{-1} 8$-HQS, $5 \mu \mathrm{M}$ TDZ or $5 \mu \mathrm{M} \mathrm{TDZ}+150 \mathrm{mg}^{-1} 8$-HQS

\begin{tabular}{|c|c|c|c|c|}
\hline Time (days) & Control & $150 \mathrm{mg} \mathrm{l}^{-1} 8$-HQS & $5 \mu \mathrm{M} \mathrm{TDZ}$ & $5 \mu \mathrm{M} \mathrm{TDZ}+8-\mathrm{HQS}$ \\
\hline 0 & $167 \pm 47$ & - & - & - \\
\hline 5 & $272 \pm 111$ & $146.6 \pm 17.7$ & $126.1 \pm 18.7$ & $127.0 \pm 15.6$ \\
\hline 10 & $1249 \pm 271$ & $269.4 \pm 81.0$ & $159.4 \pm 34.5$ & $240.1 \pm 42.9$ \\
\hline 14 & $1322 \pm 197$ & $224.9 \pm 60.8$ & $136.2 \pm 13.0$ & $217.1 \pm 48.8$ \\
\hline \multicolumn{5}{|l|}{ ANOVA two-way analysis of variance } \\
\hline \multirow[t]{2}{*}{ Treatments } & \multicolumn{4}{|c|}{ Post-harvest life (days) } \\
\hline & 0 & 5 & 10 & 14 \\
\hline Control versus 8-HQS & - & $* *$ & $* * *$ & $* * *$ \\
\hline Control versus $5 \mu \mathrm{M}$ TDZ & - & $* *$ & $* * *$ & $* * *$ \\
\hline Control versus $5 \mu \mathrm{M}$ TDZ +8 -HQS & - & $* * *$ & $* * *$ & $* * *$ \\
\hline 8-HQS versus $5 \mu \mathrm{M}$ TDZ & - & ns & * & ns \\
\hline 8 -HQS versus $5 \mu \mathrm{M}$ TDZ +8 -HQS & - & ns & ns & ns \\
\hline $5 \mu \mathrm{M}$ TDZ versus $5 \mu \mathrm{M}$ TDZ +8 -HQS & - & ns & ns & ns \\
\hline
\end{tabular}

Values are the means $\pm \mathrm{SD}$ of 6 leaves randomly harvested at $0,5,10$ and 14 days since when cut flowers where placed in vase. Data were subjected to two-way analysis of variance and differences among treatments were analyzed by Bonferroni post-test. Each treatment was compared to all the other treatments. The asterisks denote significant differences at $* p<0.05, * * p<0.01$ and *** $p<0.001$.

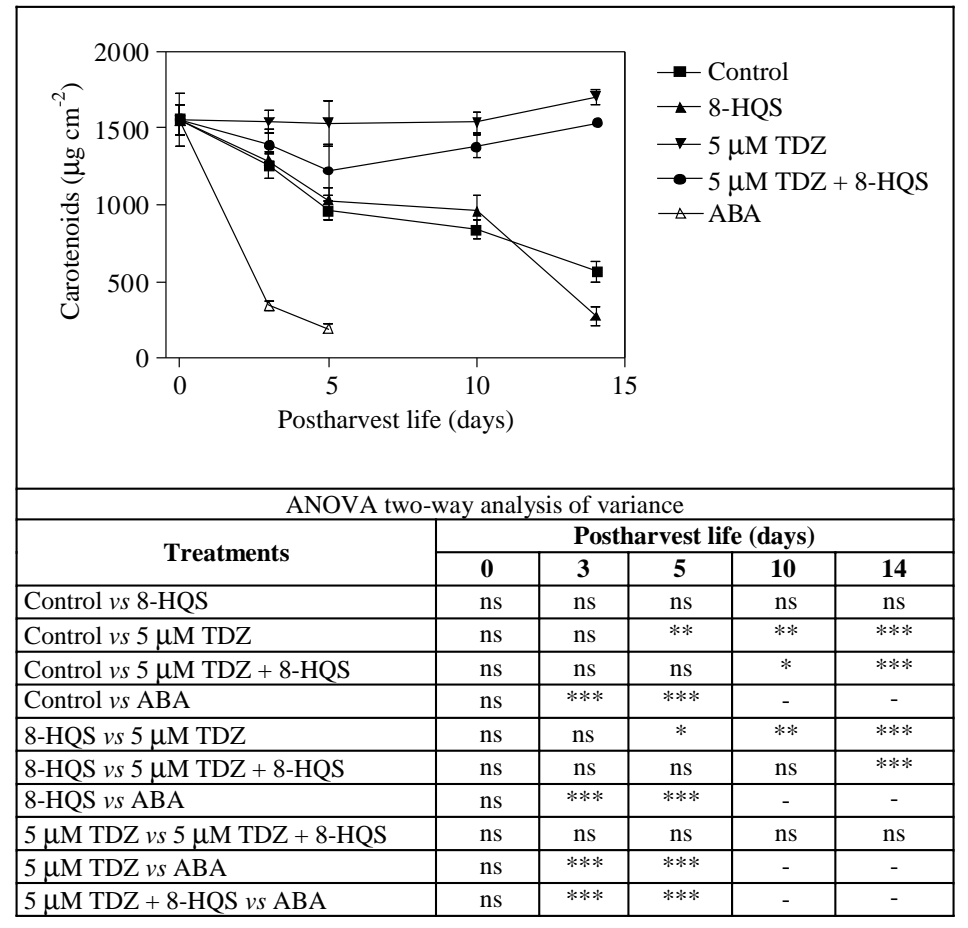

Figure 5. Total concentration carotenoids $\left(\mu \mathrm{g} \mathrm{cm}^{-2}\right.$ ) of cut stock leaves (Matthiola incana) harvested from cut flowers pulse treated for $24 \mathrm{~h}$ with distilled water (control), $150 \mathrm{mg} \mathrm{l}^{-1} 8$ - $\mathrm{HQS}, 5 \mu \mathrm{M} \mathrm{TDZ}$ or $5 \mu \mathrm{M} \mathrm{TDZ}+150 \mathrm{mg} \mathrm{l}^{-1} 8$-HQS and $100 \mu \mathrm{M} \mathrm{ABA}$. After the pulse treatment the vase solutions were replaced with distilled water. Values are the means \pm SD of six leaves randomly harvested at 0 , 3, 5, 10 and 14 days since when cut flowers where placed in vase (post-harvest life). Data were subjected to two-way analysis of variance and differences among treatments were analyzed by Bonferroni post-test. Each treatment was compared to all the other treatments. The asterisks denote significant differences at $* p<0.05,{ }^{* *} p<0.01$ and $* * * p<0.001$.

might be degraded to ABA through the indirect $\mathrm{C}_{40}$ ABA pathway (Milborrow 2001). Applications of cytokinins are able to inhibit leaf yellow- ing and may inhibit ABA increase. Cytokinins reduce ABA biosynthesis through a feed-back inhibition of intermediate metabolites that leads to 
isopentenyl diphosphate, a step common to both carotenoid and cytokinin biosynthesis. This compound is a precursor shared between the chlorophyll and the carotenoid biosynthesis pathways. The effect of cytokinins on the reduction of ABA accumulation has been observed during flower senescence of transgenic petunia (Chang et al. 2003). In our experiment, TDZ, being a cytokininlike compound, inhibited carotenoid degradation and may have inhibited ABA biosynthesis; in fact, the ABA concentration did not change with time.

Treatment with TDZ increased leaf pigments; the chlorophyll concentration measured after 30 days of vase life was higher than the initial value (data not shown). Analogous results were observed in cut eucalyptus foliage, cut chrysanthemum and cut tulips treated with TDZ; all three showed a significant increase in chlorophyll concentration compared to the initial values measured at harvesting time (Ferrante et al. 2002a, b, 2003).

The combination of TDZ with 8-HQS seems to temporarily reduce the positive effect of TDZ on chlorophyll and carotenoid content and the later recovery might be due both to a loss of effect of 8HQS and to the persistence of TDZ. The loss of chlorophyll and carotenoids in cut flowers can be associated with the slight increase in ABA content without water stress conditions (Figure 1). This result confirms the hypothesis that, during senescence, carotenoids may be converted to ABA.

8-HQS was applied to avoid water stress, which could induce ABA biosynthesis (see review, Seki et al. 2003). In fact, it is well known that a rise in ABA is triggered by water stress. 8-HQS is a common floral preservative with biocide properties that inhibits bacteria growth and xylem occlusion (van Doorn 1997). The RWC did not change even in TDZ without 8-HQS; this result is probably due to the better leaf health status or to the absence of vessel occlusion during vase life.

In conclusion, results suggest that, during leaf yellowing, carotenoids might be converted to ABA, which might not play a primary role in the initiation of leaf yellowing. In fact, ABA increased significantly in field-grown soybeans during leaf senescence, after which, protein and chlorophyll started to decline (Samet and Sinclair 1980). However, ABA has an effect on promoting chlorophyll degradation, as already observed in water stressed plants (Aharoni and Richmond 1978; Mumtaz et al. 1997). A hypothesis of the role of
$\mathrm{ABA}$ during leaf senescence could be that $\mathrm{ABA}$ is not the main factor involved in leaf yellowing, but its presence and accumulation may have a synergic effect with other senescence inducers (ethylene, hormone imbalance, etc.) and it dramatically accelerates leaf senescence.

\section{References}

Aharoni N. and Richmond A.E. 1978. Endogenous gibberellin and abscisic-acid content as related to senescence of detached lettuce leaves. Plant Physiol. 62(2): 224-228.

Ben-Jacoov J., Poole R.T. and Conover C.A. 1985. Long term dark storage of Dieffenbachia sprayed with cytokinins. Gartenbauwissenschaft 50: 19-22.

Biswall B. 1995. Carotenoid catabolism during leaf senescence and its control by light. Photochem. Photobiol. B 30: 3-14.

Chang H., Jones M.L., Banowetz G.M. and Clark D.G. 2003. Overproduction of cytokinins in petunia flowers transformed with PSAG12-IPT delays corolla senescence and decreases sensitivity to ethylene. Plant Physiol. 132: 2174-2183.

Cowan A.K. and Richardson C.R. 1993. The biosynthesis of abscisic acid from all-trans-b-carotene in a cell-free system from Citrus sinensis exocarp. Plant Cell Physiol. 34: 969-972.

Crozier A., Kamiya Y., Bishop G. and Yokota T. 2000. Biosynthesis of hormones and elicitor molecules. In: Buchanan B.B., Gruissem W. and Jones R.L. (eds), Biochemistry \& Molecular Biology of Plants. ASPB, Rockville, MD.

Demmig-Adams B., Gilmore A.M. and Adams W.W. 1996. In vivo functions of carotenoids in higher plants. FASEB 10: 403-413.

Ferrante A., Hunter D.A., Hackett W.P. and Reid M.S. 2002a. Thidiazuron - a potent inhibitor of leaf senescence in Alstroemeria. Postharvest Biol. Technol. 25(3): 333-338.

Ferrante A., Mensuali-Sodi A., Serra G. and Tognoni F. 2002b. Effects of ethylene and cytokinins on vase life of cut Eucalyptus parvifolia Cambage branches. Plant Growth Regul. 38: 119-125.

Ferrante A., Mensuali-Sodi A., Serra G. and Tognoni F. 2003. Treatment with thidiazuron for preventing leaf yellowing in cut tulips, and chrysanthemum. Acta Hort. 624: 357-363.

Hicklenton P.R. 1991. GA and benzylaminopurine delay leaf yellowing in cut Alstroemeria stems. HortScience 26(9): 1981199.

Lee H.S. and Milborrow B.V. 1997a. Endogenous biosynthetic precursors of abscisic acid. IV. Biosynthesis of ABA from $\left[{ }^{2} \mathrm{H}_{n}\right]$ carotenoids by a cell-free system from avocado. Aust. J. Plant Physiol. 24: 715-726.

Lichtenthaler H.K. 1987. Chlorophylls and carotenoids: pigments of photosynthetic membranes. Meth. Enzymol. 148: $350-382$.

Matile P. 2000. Biochemistry of Indian summer: physiology of autumnal leaf coloration. Exp. Gerontol. 35: 145-158.

Milborrow B.V. 2001. The pathway of biosynthesis of abscisic acid in vascular plants: a review of the present state of knowledge of ABA biosynthesis. J. Exp. Bot. 359(52): 11451164. 
Mumtaz S., Naqvi S.S.M., Shereen A. and Khan M.A. 1997. Salinity stress and the senescence process wheat in (Triticum aestivum L.). Pakistan J. Bot. 29(2): 299-303.

Niyogi K.K., Grossman A.R. and Björkman O. 1998. Arabidopsis mutants define a central role for the xanthophylls cycle in the regulation of photosynthetic energy conversion. Plant Cell 10: 1121-1134.

Pardossi A., Vernieri P. and Tognoni F. 1991. Evaluation of the pressure chamber method for the assessment of water status in chilled plants. Plant Cell Environ. 14(7): 675-682.

Samet J.S. and Sinclair T.R 1980. Leaf senescence and abscisic acid in leaves of field-grown soybean. Plant Physiol. 66(6): 1164-1168.

Seki M., Kamei A., Yamaguchi-Shinozaki K. and Shinozaki K 2003. Molecular responses to drought, salinity and frost: common and different paths for plant protection. Curr. Opin. Biotechnol. 14(2): 194-199.
Van Doorn W.G. 1997. Water relations of cut flowers. Hort. Rev. 18: 1-47.

van Staden J., Cook E.L. and Nooden L.D. 1988. Cytokinins and senescence. In: Nooden L.D. and Leopold A.C. (eds), Senescence and Aging in Plants. Academic Press Inc., San Diego, CA.

Vernieri P., Pardossi A. and Tognoni F. 1991. Influence of chilling and drought on water relations and abscisic-acid accumulation in bean. Aust. J. Plant Physiol. 18(1): 25-35.

Weaver L.M., Gan S., Querino B. and Amasino R.M. 1998. A comparison of the expression patterns of several senescenceassociated genes in response to stress and hormone treatment. Plant Mol. Biol. 37: 455-469.

Zacarias L. and Reid M.S. 1990. Role of growth regulators in the senescence of Arabidopsis thaliana leaves. Physiol. Plant. 80: $549-554$. 